"Á la vuelta de pocos años tendríamos regenerado nuestro servicio doméstico".

Las escuelas de sirvientas en la ciudad de Córdoba (Argentina, primeras décadas del siglo XX)

Fernando J. REMEDI

Avances del Cesor, V. XVII, № 22, junio 2020, pp. 1-21.

ISSNe 2422-6580 / ISSN 1514-3899 - http://web2.rosario-conicet.gov.ar/ojs/index.php/AvancesCesor/index

\title{
"Á la vuelta de pocos años tendríamos regenerado nuestro servicio doméstico". Las escuelas de sirvientas en la ciudad de Córdoba (Argentina, primeras décadas del siglo XX)*
}

\author{
"In a few years, we would have \\ our domestic service regenerated". \\ Maid schools in the city of Córdoba \\ (Argentina, first decades of the $20^{\text {th }}$ century)
}

Fernando J. Remedi

Instituto de Estudios Históricos

Centro de Estudios Históricos "Prof. Carlos S. A. Segreti" Consejo Nacional de Investigaciones Científicas y Técnicas

Universidad Nacional de Córdoba (Argentina) fremedi@yahoo.com.ar

Recibido: 14-11-2018

Aceptado: $10-05-2019$

Publicado: 05-06-2020

\footnotetext{
*. Una versión breve y preliminar de este trabajo fue presentada en las X Jornadas de Historia Moderna y Contemporánea. Guerra y paz en la Edad Moderna y Contemporánea, Universidad Nacional de Salta, Salta, 29 al 31 de Agosto de 2018.
} 


\title{
Resumen
}

Este trabajo se inserta en una línea de investigación sobre los pobres y la pobreza en Córdoba, Argentina, en el marco de grandes transformaciones producidas entre fines del siglo XIX y las primeras décadas del siglo XX, como la modernización material y social, la urbanización, la institucionalización estatal y el crecimiento económico. Dichos cambios fueron acompañados de una serie de desajustes sociales que afectaron a los sectores populares. En este contexto emergió un conjunto de prácticas destinadas a mitigar el déficit material y moral de esos grupos, que dibujaron fronteras difusas y móviles entre la sociedad civil y el Estado en la distribución de bienestar y la asistencia a los pobres. Nuestra atención se concentra en el servicio doméstico, integrado mayormente por mujeres pobres. En esta línea, este trabajo estudia las denominadas "escuelas de sirvientas" existentes en la ciudad de Córdoba en las décadas de 1910 y 1920, gestionadas por organizaciones benéficas y/o religiosas; se examinan sus objetivos y funciones, funcionamiento e impacto sobre el mercado laboral y sobre las domésticas. Se utiliza sobre todo la prensa, memorias de asociaciones benéficas y documentación administrativa de la Municipalidad de Córdoba.

Palabras Clave: servicio doméstico, pobres, beneficencias, políticas sociales, asistencia social

\begin{abstract}
This work can be framed within a research area about the poor and poverty in Córdoba, Argentina, in the context of transformations produced between the end of the $19^{\text {th }}$ century and the first decades of the $20^{\text {th }}$ century, such as material and social modernization, urbanization, state institutionalization and economic growth. These transformations were accompanied by a series of social imbalances that affected the low-income sectors. In this context, a set of practices seeking to mitigate material and moral deficit of these sectors emerged. These practices drew up vague and moving limits between civil society and the State in the distribution of welfare and assistance to the poor. Our attention focuses on the domestic service, made up mostly of poor women. In this area, this work analyses the so-called "maid schools" that existed in the city of Córdoba in the decades of 1910 and 1920. These were managed by charity and/or religious organisations. We will examine their objectives and functions, their functioning and impact on the labour market and the maids. This work uses mainly the press, charity associations' reports and administrative documentation from Cordoba City Hall as their primary research sources.
\end{abstract}

Keywords: domestic service, poor, charity, social policy, social care

$$
\propto \tilde{e} \propto
$$

\section{Introducción}

Este trabajo se inserta dentro de una línea de investigación de mayor envergadura dedicada al "mundo de los pobres" en Córdoba (Argentina) en el marco de grandes transformaciones producidas entre el último tercio del siglo XIX y el primero del XX, especialmente, la modernización material y social, la urbanización, el crecimiento económico y la institucionalización estatal. Su objetivo general es esclarecer cómo los pobres 
experimentaron dichos procesos, reconstruir su impacto sobre ellos y cómo actuaron en ese marco de cambios rápidos y profundos. En efecto, desde el último tercio del siglo XIX, la Argentina experimentó un crecimiento económico duradero sustentado sobre la dinámica de un modelo primario exportador sostenido sobre el desplazamiento permanente de la frontera agropecuaria, la incorporación al mercado laboral de un significativo contingente de inmigrantes y la inversión de capitales extranjeros. Con coyunturas cambiantes, incluida una desaceleración desde 1914, ese modelo de crecimiento persistió hasta 1930.

Ubicada en el centro geográfico de la Argentina, la provincia de Córdoba participó de ese modelo económico dominante experimentando una sostenida ola de crecimiento económico, acompañada de una rápida urbanización y una significativa expansión demográfica. Unos pocos indicadores bastan para delinear la magnitud de esas transformaciones. La superficie sembrada pasó de 234.395 hectáreas en 1888 a 3.983 .655 en 1929-30; el número de cabezas de ganado lo hizo de 1.897 .985 en 1877 a 6.476 .603 en 1930 (Moreyra, 1992, p. 5). Vinculado a la expansión agrícola, se produjo un incipiente desarrollo de la actividad industrial, que se multiplicó por ocho entre 1895 y 1914, proceso que afectó muy especialmente a la ciudad de Córdoba -capital administrativa de la jurisdicción homónima (Ortiz Bergia, Reyna, Portelli y Moretti, 2015, pp. 16-20). A su vez, la población de dicha ciudad pasó de unos 34.000 habitantes en 1869 a 55.000 en $1895,130.000$ en 1914 y unos 250.000 en 1930.

Esas grandes transformaciones fueron acompañadas de una generalización de desajustes sociales que afectaron la vida de una amplia franja de los sectores populares, los cuales remitían sobre todo a sus condiciones de vida y trabajo y se expresaban en numerosas $\mathrm{y}$ diversas necesidades insatisfechas en esas materias y en múltiples situaciones de precariedad, fragilidad, vulnerabilidad y exclusión social (Ortiz Bergia, et al., 2015, pp. 24-30). ${ }^{1}$

En este marco emergió un conjunto de prácticas destinadas a paliar el déficit material y moral de los de abajo; dichas prácticas -heterogéneas, cambiantes, desplegadas por actores diversospretendían atenuar los efectos perversos del crecimiento y la modernización y en la práctica dibujaron fronteras difusas y móviles entre la sociedad civil -familia, beneficencia, Iglesia, mutualismo, etc.-, el Estado y el mercado en la distribución de bienestar y asistencia social. Inicialmente, las reacciones frente a los desajustes sociales provinieron de un modelo pluralista no planificado de atención de lo social, con fuerte predominio de la asistencia benéfica privada y limitada participación del Estado. La apelación al esfuerzo conjunto de la filantropía, la beneficencia y el Estado estaba en sintonía con la vigencia de un sistema de protección social benéfico-asistencial, de carácter mixto entre asociaciones civiles con fuerte impronta religiosa y el Estado a través del otorgamiento de subsidios, con una responsabilidad residual y no institucional (Moreyra, 2009, p. 373). Recién desde la segunda década de la centuria comenzó a avanzarse, no sin dificultades, en la conformación de lo que Moreyra (2009) denomina como "protoestado social", que concibe como una sistemática política de regulación provincial y municipal de los desajustes sociales que acompañaron al

1. Una buena síntesis de esos desajustes sociales en Moreyra (2009). 
crecimiento y el incipiente reconocimiento de algunos derechos sociales (p. 375).

Dentro de ese marco general, nuestra atención en los últimos años se focalizó en el servicio doméstico, cuyos integrantes eran pobres, mayoritariamente mujeres, a menudo menores inmigrantes. La hipótesis central e integradora en la que se avanzó en estos años sostiene que en la Córdoba del viraje del siglo XIX al XX, en sintonía con el proceso de modernización en curso, se produjo una creciente mercantilización del servicio doméstico, una transición desde un predominio de un esquema tradicional de relaciones dominado por el paternalismo y la autoridad-deferencia hacia otro marcado por la preeminencia de vínculos de naturaleza contractual y de mercado. Dicho proceso de mercantilización, aun con sus límites, contribuyó decididamente a desestabilizar las formas tradicionales de regulación del servicio y su avance provocó cierto debilitamiento del control patronal, o bien, la otra cara de la moneda, la subordinación de las domésticas fue disminuyendo y dejando paso a mayores márgenes de libertad y negociación, aunque sin trastocar la asimetría de la relación.

En esa línea de trabajo, esta contribución incursiona en las denominadas "escuelas de sirvientas" existentes en la ciudad de Córdoba en las décadas de 1910 y 1920, promovidas y regenteadas por organizaciones benéficas y/o religiosas. Se busca establecer los objetivos $\mathrm{y}$ las funciones de esas instituciones, su funcionamiento y su impacto sobre el mercado laboral y las domésticas. A tal efecto, se trabajó con información de la prensa, memorias de asociaciones benéficas y documentación administrativa de la Municipalidad de Córdoba.

\section{"Escuelas de sirvientas" y "regeneración" del servicio doméstico}

De acuerdo con los datos del Censo Municipal de Córdoba de 1906 (Córdoba, 1910, p. 59), las personas mayores de 14 años que se desempeñaban como "personal de servicio" eran 9.196, equivalentes al 10\% de la población de la ciudad. ${ }^{2}$ Sobre la base de esos datos estadísticos, una mirada al interior de esa categoría censal revela un nítido sesgo de género y nacionalidad en ese personal: $95 \%$ eran mujeres y $92 \%$ argentinos. En cuanto a la distribución por ocupaciones dentro de la categoría, se observa que 6 de las 22 contempladas agrupan cantidades superiores al $10 \%$, mientras que todas las restantes no llegan al 1\%. Entre aquellas se ubican, en orden decreciente de importancia -comprendiendo hombres y mujeres-, las "lavanderas" (23\%), los "trabajos domésticos" (22\%), los "mucamos" (16\%), los "cocineros" (12\%), los "domésticos" (11\%) y, finalmente, los "planchadores" (11\%). Las demás categorías, casi insignificantes desde el punto de vista estrictamente cuantitativo, son amas de llave y de leche, niñeras, caballerizos, serenos, caseros, mozos de café, entre otras. Entre las mujeres predominan las lavanderas (24\%), seguidas muy de cerca por las dedicadas a "trabajos

2. Esa cifra es apenas un piso para la dimensión del servicio doméstico, por el subregistro debido a la naturaleza de la actividad y la invisibilización de muchos menores de ambos sexos por el criterio censal de contabilizar sólo a los individuos de 14 años o más para la clasificación por oficios. Expedientes judiciales, crónicas policiales y avisos de empleo de la prensa indican la presencia frecuente de niños/as en el servicio doméstico de la época. Un indicador cuantitativo provisto por Viel Moreira (2005) es por demás significativo: en 1904, en la ciudad de Córdoba, 2.635 menores habían sido colocadas en casas particulares por la actuación de sólo una de las dos secciones existentes de la Defensoría de Menores ( $\mathrm{p}$. 233). 
domésticos" (23\%), más lejos las mucamas $(15 \%)$, cocineras $(12 \%)$, planchadoras $(12 \%)$, “domésticas" en general (11\%), entre las principales ocupaciones. En el caso de los hombres, son mayoría los mucamos (26\%), seguidos por los cocineros (17\%), planchadores (13\%), "domésticos" (13\%) y porteros y mozos de café con una participación semejante (8\%), entre las principales ocupaciones.

La amplia mayoría de mujeres dentro del servicio doméstico de la época es un indicador de los avances alcanzados por el proceso de feminización que experimentaba dicha actividad. En el caso de la ciudad de Buenos Aires, la participación mayoritaria de las mujeres en el servicio doméstico pasó del 70 al 90\% en el período intercensal 1869-1914 y trepó hasta $94 \%$ en 1947 y $97 \%$ en 1960 (Allemandi, 2017, p. 75). Por otra parte, la feminización de la actividad remite también a las concepciones dominantes en la época, en concreto al creciente acercamiento de aquella al trabajo doméstico no remunerado, más precisamente a la figura del ama de casa (Pérez, 2018a, pp. 78 y 233). Hay que tener presente que en la Argentina de entre siglos, incluida Córdoba, la incorporación de las mujeres al mercado laboral fue concebida como una situación excepcional, consecuencia forzosa de las estrecheces económicas que hacían peligrar la reproducción cotidiana, personal y familiar. Dicho principio de "excepcionalidad" fue reforzado por las ideas de "transitoriedad y complementariedad" que atravesaban la cuestión del trabajo femenino asalariado. Por un lado, este último era concebido como fruto de una salida sólo transitoria del mundo doméstico y hogareño; por otro, la retribución femenina se estimaba como un suplemento del salario masculino que ingresaba en el hogar familiar, lo cual fue un vigoroso soporte ideológico subyacente a la discriminación salarial en desmedro de mujeres e infantes en el mercado de trabajo (Allemandi, 2017, p. 37; Pérez, 2018b, p. 20).

A lo expuesto debe añadirse la vigencia extendida y dominante en dicho contexto histórico de una división generizada del trabajo que contribuyó a una segregación ocupacional, vale decir, a la creación de espacios laborales socialmente diferenciados y jerarquizados, que operó en desmedro de las mujeres, confinándolas en unos pocos sectores de actividad de bajos niveles de productividad y de salarios (Allemandi, 2017, p. 47). Más en general, en virtud de la distribución socialmente sancionada de roles por entonces dominantes, las tareas domésticas fueron asignadas a las mujeres, como parte de su propia "naturaleza" femenina, y su desenvolvimiento conllevaría su realización personal al permitirles desplegar atributos propios de su sexo, como el espíritu de sacrificio, la abnegación, la sensibilidad, entre otros (Vázquez Lorda, 2010, p. 108).

En el caso del servicio doméstico, la realización de las tareas de este tipo era delegada -total o parcialmente- en otras mujeres que se encargaban de ellas en tanto empleadas o criadas. Sin embargo, ello no eximía a las "dueñas" o "señoras de casa" -las patronasde sus obligaciones domésticas, en tanto les correspondía la dirección, la supervisión y el entendimiento con el personal de servicio. Patronas y empleadas mantenían una relación jerárquica y desigual, a la vez que compartían posiciones de subordinación dentro del orden patriarcal vigente (Vázquez Lorda, 2010, p. 109). De este modo, el servicio doméstico puede ser visto como un espacio de experiencias y de relaciones sociales asimétricas, interclasistas y crecientemente feminizado. 
En ese sentido, en 1912, en una nota publicada por la prensa católica de la ciudad de Córdoba, bajo el título "La crisis de los sirvientes. Es una plaga universal”, su autora -Martha- exponía sus preocupaciones, inquietudes y pareceres acerca del estado del servicio doméstico en esos momentos. Para ella se habían acabado "los buenos servidores" y en parte eso era responsabilidad de las dueñas de casa que -a diferencia de lo acontecido en el pasado con sus abuelas- ya no mostraban interés por el personal de servicio $y$, además, a menudo lo maltrataban. A consecuencia de ello, patronas y domésticas habían devenido extrañas y, aún más, enemigas; Martha sentenciaba: "Los sirvientes se han convertido en nuestros enemigos, pasan como extranjeros en la casa, nos engañan y de todas maneras, trabajan apenas y desconfían de sus patrones". ${ }^{3}$ Para ella, la solución a ese inquietante problema era recuperar las buenas costumbres de su abuela, interesarse por el personal de servicio, su salud, sus problemas, circunstancias de vida, familia, etc. de manera de granjearse su confianza, influirlo y afirmar sus creencias religiosas; en suma, se trataba de ser "buenas dueñas de casa". Al finalizar su artículo, Martha exhortaba a sus pares diciéndoles:

Buscad buenas muchachas, tratadlas bien, tened paciencia con sus defectos y su ignorancia, no le mostréis desdeño alguno, ni adversión. Por el contrario, hacedles ver que os interesáis de sus costumbres y de su porvenir, y encontraréis en ellas, buenas y fieles servidoras. ${ }^{4}$

3. Martha (17 de abril de 1912). La crisis de los sirvientes. Es una plaga universal. Los Principios $(L P)$, p. 7. Archivo del Arzobispado de Córdoba (AAC), Córdoba.

4. Martha (17 de abril de 1912). La crisis de los sirvientes. Es una plaga universal. LP, p. 7.

6
Días después de ese artículo, otra dueña de casa -Blanca-, atendiendo a "las lamentaciones de Martha", a las cuales estimaba "justísimas y como el eco de toda una sociedad profundamente preocupada con el difícil problema del mal servicio doméstico", proponía una solución al mismo: instaba a la atribulada Martha y sus demás congéneres a enviar a sus domésticas a la denominada Escuela Patronato. ${ }^{5}$

Pero Martha y Blanca eran la caja de resonancia de una cuestión que parecía perturbar a la sociedad cordobesa de la época, preocupada y quejosa por el comportamiento y el desempeño del servicio doméstico. Como se estableció en otros trabajos (Remedi, 2011, 2012, 2014a), los reclamos no apuntaban sólo -ni principalmente- a la preparación y/o competencia de las trabajadoras, sino también y mucho más a sus comportamientos -considerados impertinentes, altaneros, pretenciosos, desmesurados-, además de sus condiciones morales, sobre las cuales casi siempre caía un manto de dudas. A todo ello se añadía, por la creciente mercantilización del servicio doméstico en el período, un debilitamiento (o la ausencia) de lazos de fidelidad entre trabajadoras y patronas. Esta cuestión no es menor si se atiende a la complejidad de la relación patronasdomésticas, que involucraba un vínculo laboral, de orden económico, pero también componentes afectivos, de variada intensidad según el caso considerado. En este sentido resulta interesante la sugerencia de Higgs recogida y reproducida por Pérez- de examinar el trabajo doméstico remunerado más como una serie de relaciones sociales con un contenido de trabajo similar en un espectro que

5. Blanca (23 de abril de 1912). La escuela-patronato. $L P$, p. 7. 
va desde el parentesco cercano hasta el nexo puramente económico, más que simplemente como una "ocupación" (Pérez, 2018b, p. 17). La ya aludida Blanca era muy consciente de esta situación y sin ambages exhortaba a sus pares dueñas de casa en el sentido de que debían ganarse el amor de sus domésticas:

Impongámonos (...) el deber de hacernos amar de nuestros criados antes que hacernos temer. (...) no por la indiscreta tolerancia á todos sus defectos y caprichos sino por la tierna y bondadosa solicitud para con sus ignorancias y sus necesidades. ${ }^{6}$

Tal como lo entendían Blanca y Martha, pero no solamente ellas, era necesario -en sus palabras- regenerar el servicio doméstico para contar con buenas sirvientas. Para ello, el medio era promover la elevación material y sobre todo moral de las domésticas y uno de los instrumentos previstos eran las "escuelas de sirvientas". Así se motorizaría la "regeneración del servicio doméstico", que Blanca apreciaba como "una de las grandes necesidades de nuestro país". ${ }^{7}$ Cuatro años después, una de las damas que impulsaban esas instituciones apuntaba que su funcionamiento ya dejaba sentir "su benéfica y regeneradora acción en ésta clase obrera", en alusión a las domésticas. ${ }^{8}$

6. Blanca (23 de abril de 1912). La escuela-patronato. $L P$, p. 7. Un año más tarde, en un discurso de tono nostálgico y añorante de tiempos que consideraba pasados, el periódico evocaba esas dimensiones más afectivas que permeaban el vínculo patrones/as-servicio: "Pasaron los tiempos en que el personal de servicio era considerado como de familia. (...) el personal doméstico de antaño merecía esa consideración: era fiel y cuidaba y atendía los intereses de sus 'amos' como si fueran propios." Feminismo doméstico (11 de marzo de 1913). LP, p. 2.

7. Blanca (23 de abril de 1912). La escuela-patronato. $L P$, p. 7.

8. María J. del Campillo, Presidenta de la Asociación de la Propaganda Católica, al Presidente del Concejo
Al menos una institución de ese tipo ya había sido puesta en marcha en la ciudad a fines del siglo XIX, la denominada "escuela práctica de sirvientas" o colegio/asilo práctico -como solía conocérsela-, que funcionaba bajo el patrocinio de la Conferencia Nuestra Señora de Copacabana de la Sociedad de San Vicente de Paul. No obstante, resulta muy sugestivo que hacia la década de 1910 irrumpen en Córdoba varias escuelas de esa naturaleza. Estas nuevas instituciones se distinguían de la fundada en 1879 , sobre todo en el perfil de las destinatarias y de sus acciones. A diferencia de aquellas, su semejante de fines del siglo XIX se destinaba únicamente a niñas desvalidas, desamparadas y/o huérfanas que, internas en la institución, eran formadas para el servicio doméstico y colocadas en éste por las vicentinas. En este sentido, no puede perderse de vista la complejidad y heterogeneidad de dicho sector en la Córdoba de la época, donde las situaciones variaban desde la existencia de una relación contractual, libremente establecida, entre patronas y trabajadoras asalariadas, hasta la colocación forzosa de menores como personal de servicio en una familia por sus padres o tutores, la beneficencia y/o la Defensoría de Menores, donde se desempeñaban como tal a menudo sólo a cambio de su subsistencia (Remedi, 2012, pp. 53-61). ${ }^{9}$ La coexistencia de situaciones tan dispares, que seguramente conllevaron experiencias de

Deliberante, 25 de agosto de 1916. Documentos, 1917, f. 209. Archivo Histórico Municipal de Córdoba (AHMC), Córdoba.

9. Para la ciudad de Buenos Aires de entre siglos se evidencia una situación semejante a la señalada, donde coexistían diversos arreglos de trabajo, formas remunerativas y prácticas de colocación y crianza de menores; en ese contexto, dentro del servicio doméstico se congregaban personas libres con capacidad de acordar condiciones contractuales con otras jurídicamente inferiorizadas que eran tuteladas y expuestas a regímenes forzados de trabajo. (Allemandi, 2017, pp. 241-243). 
domesticidad disímiles, define un límite significativo del proceso de mercantilización del servicio doméstico que estaba en marcha.

En la ciudad de Córdoba, hacia la década de 1910, funcionaron al menos cuatro "escuelas de sirvientas", todas bajo la impronta del catolicismo, sostenidas por organizaciones benéficas y/o religiosas y gestionadas por damas de la elite. Dos de ellas funcionaron bajo el patrocinio de la Asociación Propaganda Católica, otra lo hizo con el de la Asociación Apostolado de la Oración de la Iglesia del Carmen -fundada en 1909- y la última, puesta en marcha en 1916, fue la Escuela Dominical San José de Calasanz. Es muy llamativo que dichas fundaciones se produjeron en momentos en que arreciaban los comentarios, las quejas y los reclamos por la situación del servicio doméstico por parte de contemporáneos y de la prensa.

Esas escuelas eran parte de la respuesta de la sociedad civil a la "descompostura" del servicio doméstico en el período, porque con ellas se buscaba colaborar en la solución de este problema en su dimensión laboral y, sobre todo, moral. Se trataba de "reparar uno de los males más grave [sic] [problema] de que se lamenta nuestra actual sociedad" -se expresaba en la prensa católica- como era "el estar tan maleado el servicio doméstico". ${ }^{10} \mathrm{El}$ objetivo declarado de la Escuela Patronato impulsada por el Apostolado de la Oración era "formar buenas sirvientas", ${ }^{11}$ a la vez que la escuela de sirvientas de la Propaganda Católica era mantenida porque la entidad -según se declaraba en la prensa a fines de los años '20- estaba "compenetrada de la necesidad de

10. Escuela-Patronato (28 de marzo de 1911). LP, p. 2.

11. Escuela-Patronato (17 de marzo de 1914). LP, p. 4.

8 formar un servicio doméstico respetuoso, apto para los quehaceres domésticos y consciente de sus deberes" ${ }^{12}$ Palabras más o menos, tal como lo requería Martha, se trataba de que esas escuelas colaboraran en formar "buenas y fieles servidoras". ${ }^{13}$

Con esas finalidades, en esas instituciones las domésticas recibían instrucción general básica -lectura,escritura,aritmética,etc.-, capacitación para el ejercicio de su oficio y clases de religión y moral, a cargo de sacerdotes, que apuntaban a desarrollarlas como personas creyentes, de bien, de fe, virtud y piedad. Ajustándonos más a las concepciones vigentes en el interior de esas escuelas, la enseñanza-aprendizaje de la religión y la moral parecen haber ocupado el sitio de privilegio frente a los demás contenidos. En las escuelas de la Propaganda Católica las prioridades eran claras, si nos atenemos al discurso de la asociación. Se sostenía que para contar con un servicio "adornado del grado de instrucción y moralidad" que requería el hogar, se debía instruir a las domésticas "ante todo, en la religión y moral cristiana, en las labores más propias de la mujer, como el corte, confección y cocina, haciendo finalmente que se hallen instruidas, siquiera en los rudimentos más precisos, de lectura, escritura y aritmética". ${ }^{14}$ Las prioridades, los contenidos y el nivel de profundidad de los mismos que se contemplaban en la enseñanza de esas escuelas parecen muy claros. Sus objetivos apuntaban -en palabras de la presidenta de la asociación-

12. La Escuela Dominical para Jóvenes Empleadas (17 de marzo de 1929). LP, p. 3.

13. Martha (17 de abril de 1912). La crisis de los sirvientes. Es una plaga universal. $L P$, p. 7 . Destacado del autor.

14. Feminismo de buena ley (4 de marzo de 1920). LP, p. 4. 
hacia "la instrucción y moralización de las jóvenes empleadas en el servicio doméstico". ${ }^{15}$ Idéntica situación se observa en la Escuela Patronato del Apostolado de la Oración, como se infiere de sus estatutos sociales, donde se declaraba que dicha entidad educativa tenía entre sus finalidades "en primer lugar, moralizar á la mujer obrera instruyéndola en sus deberes religiosos, procurando además inculcarle el amor á la virtud y al trabajo (...) En segundo lugar se instruye á las asociadas en sus deberes domésticos por medio de clases prácticas en las diversas ramas que abraza el buen servicio doméstico." ${ }^{16}$ Asimismo, en la Memoria de la institución de 1914 se afirmaba que ella había sido "fundada con el fin de moralizar y educar el gremio de sirvientas, desgraciadamente tan descuidado". ${ }^{17}$ Más allá de Córdoba, preocupación semejante de las mujeres católicas por la educación y la moralización de las domésticas -incluidas las propias- persistió en décadas posteriores y se plasmó, entre otras iniciativas, en la publicación en los años ' 40 de un boletín titulado Trabajo y $\mathrm{Fe}$, editado por la Acción Católica Argentina. Con esta publicación las mujeres de la asociación pretendían -siguiendo a Vázquez Lorda (2010)- contribuir a educar, corregir y formar a las domésticas católicas, poniéndolas en conocimiento de la mejor manera de cumplir con sus deberes y de hacerlo en el marco de los valores cristianos. La mujer interpelada por el boletín era una doméstica soltera, joven, católica, principalmente procedente del

15. María J. del Campillo, Presidenta de la Asociación de Propaganda Católica, al Intendente Henoch Aguiar, 30 de julio de 1915. Documentos, 1915, f. 75r. AHMC, Córdoba.

16. Escuela-Patronato (28 de marzo de 1911). LP, p. 2.

17. Escolares. Escuela Patronato de Sirvientas (2 de diciembre de 1914). LP, p. 4. interior, por lo cual se hallaba sola en Buenos Aires, expuesta a los peligros que comportaba la gran ciudad (pp. 114-115, 119).

En realidad, la instrucción básica y, mucho más aún, la formación de competencias para el desempeño como domésticas estaban íntimamente entrelazadas con la misión moralizadora, reforzándola, porque se confiaba en la capacidad del trabajo y el conocimiento para promover la moral y la virtud. Las palabras del Padre Font, de la Compañía de Jesús, director de la Propaganda Católica y guía espiritual de las escuelas de sirvientas patrocinadas por ella, son especialmente reveladoras. En el acto de clausura del curso, el religioso recomendaba a las damas encargadas de la gestión de esas escuelas "la continuación en el camino emprendido para desterrar la ignorancia y fomentar la virtud por medio de la ilustración y el trabajo". ${ }^{18}$ Así, se entendía que el funcionamiento de las escuelas de sirvientas redundaría en beneficio de las domésticas, las patronas y sus familias y, más en general, la sociedad en su conjunto, merced al mejoramiento -especialmente moral- de aquellas. ${ }^{19}$

Conforme con los objetivos explicitados, en términos generales, las escuelas de sirvientas compartían lineamientos semejantes en materia educativa; en todos los casos, se trataba de una combinación de religión y moral, instrucción primaria básica -lectura, escritura, caligrafía, aritmética- y en tareas domésticas agrupadas bajo la denominación de

18. Escuelas Dominicales de la Asociación Propaganda Católica (2 de diciembre de 1915). LP, p. 4.

19. Presta grandes servicios la E. dominical de calle Caseros (13 de agosto de 1927). LP, p. 2. 
Economía Doméstica y Corte y Confección. ${ }^{20}$ Recuperando y reproduciendo la división sexual del trabajo dominante, allí se enseñaban "las labores más propias de la mujer", según la voz autorizada de la Escuela de la Propaganda Católica. ${ }^{21}$

Esa situación se reproducía en la Escuela Patronato, donde las asistentes recibían instrucción primaria básica, en las tareas inherentes al servicio -labores domésticas, corte y confección, cocina y economía doméstica propiamente dicha- y en religión y moral. ${ }^{22}$ Aquí también la educación contribuía a reproducir las desigualdades de género, además de las de clase, que atravesaban a la sociedad cordobesa, ya que en "las clases de labores” a las asistentes no sólo se les enseñaba a "confeccionar sus propias ropas de vestir, sino también diversas labores propias de su clase y condición", según consignaban en la Memoria de la Escuela las damas que la regenteaban. ${ }^{23}$ Una voz calificada de la institución, orgullosa de los beneficios que ésta proveía a sus alumnas, subrayaba la tarea de la señorita a cargo de Economía Doméstica, ya que

20. María J. del Campillo, Presidenta de la Asociación de Propaganda Católica, al Intendente Henoch Aguiar. Octubre de 1914. Documentos, 1915, folios 72-73; María J. del Campillo, Presidenta de la Asociación de la Propaganda Católica, al Presidente del Concejo Deliberante. 25 de agosto de 1916. Documentos, 1917, ff. 209-210; Para las dueñas de casa (16 de mayo de 1919). $L P$, p. 2; Escuela dominical (22 de febrero de 1920). LP, p. 1; La Escuela Dominical para Jóvenes Empleadas (17 de marzo de 1929). LP, p. 3.

21. La Obra de la Propaganda Católica (5 de abril de 1918). LP, p. 7.

22. La escuela-Patronato (23 de abril de 1912). LP, p. 7; Escuela-Patronato (17 de marzo de 1914). LP, p. 4; Las escuelas dominicales (2 de noviembre de 1922). LP, p. 2.

23. Escolares. Escuela Patronato de Sirvientas (2 de diciembre de 1914). LP, p. 4. -según decía- "sus discípulas se convierten en poco tiempo en perfectas cocineras con gran satisfacción de ellas mismas (...) que pueden fácilmente colocarse en las casas de familia, y tener asegurado por este medio su porvenir" ${ }^{24}$ La instrucción primaria estaba a cargo de dos maestras normales ${ }^{25}$ y las alumnas de asistencia más regular habían aprendido a leer y escribir, "sin haber tenido al ingresar ni las más mínima noción de ello". ${ }^{26} \mathrm{La}$ enseñanza moral y religiosa estaba confiada a un carmelita descalzo- director espiritual de la institución-, a veces asistido por una laica que llevaba "la clase inferior". El religioso desempeñaba su tarea valiéndose de conferencias sobre los "deberes religiosos y domésticos" de "las muchachas afiliadas". ${ }^{27}$ En esta escuela se apelaba a los nuevos recursos provistos por la modernidad como auxiliares didácticos para el aprendizaje de religión y moral, tal como ocurría al menos el primer domingo de mes, cuando las clases de estas materias se daban "mediante una delicada colección de vistas cinematográficas que proporciona[ba] a la vez instrucción y recreo"; además, en esa oportunidad, se realizaba la comunión general de maestras y alumnas de la institución, según consta en su Memoria. ${ }^{28}$

24. Escolares. Escuela Patronato de Sirvientas (2 de diciembre de 1914). LP, p. 4.

25. Las escuelas dominicales (2 de noviembre de 1922). $L P$, p. 2.

26. Escolares. Escuela Patronato de Sirvientas (2 de diciembre de 1914). LP, p. 4.

27. La escuela-patronato (23 de abril de 1912). LP, p. 7; Escuela-Patronato (17 de marzo de 1914). LP, p. 4; Escolares. Escuela Patronato de Sirvientas (2 de diciembre de 1914). LP, p. 4; Las escuelas dominicales (2 de noviembre de 1922). LP, p. 2.

28. Escolares. Escuela Patronato de Sirvientas (2 de diciembre de 1914). LP, p. 4. 
En la Escuela Dominical San José de Calasanzpara la cual se cuenta con exigua información-, los ramos de la enseñanza eran idénticos a los de las instituciones ya aludidas, como se infiere de la composición de su plantel docente. ${ }^{29}$ $\mathrm{Al}$ igual que en las otras instituciones de su género, aquí las tareas de corte y confección apuntaban a lo más básico y necesario y a facilitar la elaboración de prendas por y para las propias alumnas. En una crónica sobre la exposición de labores de la Escuela Dominical San José de Calasanz, su autor deslizaba una ácida crítica hacia la labor benéfica de otras instituciones cuando expresaba que lo distintivo de los trabajos expuestos -como había constatado en su visita al evento- era "la parte eminentemente práctica de los mismos, no reduciéndose la exposición a un vano alarde de prendas lujosas y de bordados costosos, que rara vez hubieran de utilizar las alumnas, dada la clase social a que pertenecen". ${ }^{30}$

En las cuatro escuelas consideradas, la enseñanza focalizaba en un perfil específico de destinatarias claramente definido: exclusivamente mujeres y ya dedicadas al servicio doméstico. De aquí que los avisos publicados en la prensa por las autoridades de las asociaciones femeninas que gestionaban dichas instituciones interpelaran a las dueñas de casa -a sí mismas y sus pares de clase social, encargadas de la supervisión de las domésticas

29. El Padre Antonio Martínez, Rector del Colegio Escuelas Pías era profesor de religión; la sra. Marta Amuchástegui, maestra de instrucción primaria; la srta. María Brandalise, de corte y confección; la srta. Rosario Centeno, de labores; y las srtas. Elisa Schneider y María Herminia Casavaca Gallo, de economía doméstica. Escuela Dominical de S. José de Calasanz (28 de noviembre de 1916). LP, p. 3.

30. Escuela Dominical de S. José de Calasanz (28 de noviembre de 1916). LP, p. 3. en sus hogares-, instándolas a que las enviaran a las clases. En la Escuela Patronato, los requisitos expuestos se precisaban y reforzaban en virtud de exigencias de estado civil y edad; se promocionaba como una escuela para muchachas solteras, dedicadas al servicio doméstico, que no tuvieran menos de 13 años ni más de $30 .{ }^{31}$ En la Escuela Dominical San José de Calasanz, el espectro se ampliaba levemente para incluir no sólo a domésticas en ejercicio sino también a las futuras, al interpelar a las "sirvientas y niñas pobres". ${ }^{32}$

Según las concepciones de las damas y los directores espirituales que regenteaban las escuelas, éstas contribuían -desde su lugara rehabilitar socialmente a las mujeres dedicadas al servicio doméstico, que -por su extracción social y condiciones de existencia en la pobreza- carecían de instrucción, de formación en el oficio y, sobre todo, del grado de moralidad que eran deseables en estas trabajadoras del hogar. Especialmente, allí estaban en contacto asiduo y cotidiano con los/as niños/as, familiaridad que exigía ciertas garantías de moralidad de las domésticas. Esto llevaba al periódico católico local a recomendar a sus lectoras que en la selección del personal de servicio dieran prioridad a la honradez por encima de la formación en el oficio, para evitar que sus integrantes fueran "agentes viciosos en vez de útiles auxiliares". ${ }^{33}$ Conforme a esa mirada desde arriba, el medio social en el que esas mujeres habían nacido, crecido y se desenvolvían las había privado del desarrollo

31. Escuela-Patronato (28 de marzo de 1911). LP, p. 2; Escuela-Patronato (17 de marzo de 1914). LP, p. 4.

32. Escuela Dominical de S. José de Calasanz (28 de noviembre de 1916). LP, p. 3.

33. Los criados de antaño y ogaño. Elección de los sirvientes (3 de octubre de 1920). LP, p. 4. 
moral y de la adquisición de las competencias que las hacían idóneas para el servicio tal como se lo requería, más allá de la buena voluntad o predisposición de las mismas, que- al menos a veces- se daba por descontada. En una nota sobre las escuelas de la Propaganda Católica en Los Principios se expresaba sobre las jóvenes domésticas: "sea por la deficiente educación recibida o por el ambiente que se respira en las inferiores clases del pueblo, necesitan mayor preparación y defensa para afrontar con éxito las diversas situaciones, cada vez más difíciles, que les aguardan." ${ }^{34}$ Por tanto, avisos y gacetillas de la Propaganda Católica interpelaban recurrentemente a las patronas para que enviaran a sus domésticas a dichas escuelas con mensajes del siguiente tenor: “¿Deseamos verlas cultas, atentas, morales, obsequiosas, e instruidas a nuestras jóvenes domésticas, para que no desdigan de la cultura y honorabilidad que tanto nos preciamos en nuestros hogares? Hagámoslas, pues, tales como las deseamos". ${ }^{35}$

Los esfuerzos hechos desde las escuelas de sirvientas, en cierto sentido, tenían el valor de una misión redentora; eran una manifestación más de la caridad cristiana a ejercitar con los más pobres y desvalidos. Unas expresiones de la presidenta de la Propaganda Católica, María Juárez del Campillo, son excepcionalmente

34. Feminismo de buena ley (4 de marzo de 1920). LP, p. 4; La acción de los católicos cordobeses en pro de las clases desheredadas (18 de marzo de 1921). LP, p. 1. AAC, Córdoba. En otra ocasión se señalaba: "A pesar de su buena voluntad, lamentamos con frecuencia en ellas [empleadas en el servicio doméstico] ciertas deficiencias que las inhabilitan para el debido desempeño de los cargos que se les confían". Para las dueñas de casa (16 de mayo de 1919). LP, p. 2.

35. Feminismo de buena ley (4 de marzo de 1920). LP, p. 4; La acción de los católicos cordobeses en pro de las clases desheredadas (18 de marzo de 1921). LP, p. 1.

12 explícitas sobre cómo las damas percibían a las domésticas y a las funciones de protección y redención de las mismas mediante su accionar en las escuelas. En la Memoria expuesta en la asamblea de socias en 1920, aquella decía lo siguiente sobre esas instituciones y su labor al frente de ellas:

No puedo menos que congratularme por el éxito alcanzado, mayormente cuando el elemento en quienes vais vertiendo vuestra alma es el gremio más trabajado por el mal y el más refractario a toda enseñanza. (...) una idea dada por vosotras quizás sea la única salvación de una pobre alma, que el buen Dios os ha confiado. ${ }^{36}$

Como una pequeña célula dentro del amplio y heterogéneo espacio benéfico-asistencial, esas damas desde las escuelas de sirvientas aportaban su contribución a la tarea de "hacer lo social" - como lo conceptualiza Castel (1997)-, vale decir, al trabajo sobre las miserias del capitalismo tratando de aliviarlas.

En sintonía con el perfil de las destinatarias, todas esas escuelas funcionaban únicamente los días domingos -de descanso al menos para parte del personal doméstico- y lo hacían apenas un par de horas por la tarde, entre las 2-2:30 y las 4-4:30, respectivamente. Esto era escrupulosamente vigilado por las encargadas de la gestión de las escuelas, de manera de alentar la asistencia de las domésticas y su continuidad, procurando no fatigarlas en su día de descanso con las actividades de aprendizaje. Así, en el aviso de las escuelas de la Propaganda Católica se subrayaba: "Para suavizar estas clases en días Domingos, jamás se prolongarán

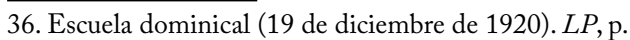
8. 
más de dos horas, de 2 a 4 p.m." ${ }^{37}$ Por sus características, esas escuelas funcionaban en locales prestados por otras instituciones, casi siempre educativas y confesionales, ubicados en la zona céntrica de la ciudad. En las décadas de 1910 y 1920 fueron muy frecuentes los desplazamientos de esas escuelas por distintos locales, especialmente el de las dos dependientes de la Propaganda Católica -Nuestra Señora de Dolores y San Francisco Javier-, que evidenciaron una particular inestabilidad de sus sedes. El ciclo lectivo se extendía entre marzo o abril y noviembre o, a más tardar, mediados de diciembre.

Un indicador del impacto de esas escuelas sobre el mercado del servicio doméstico de la época es el número de trabajadoras asistentes, para lo cual las fuentes disponibles ofrecen algunos datos que sirven como órdenes de magnitud. En principio, podría decirse que el impacto sobre el sector -en términos cuantitativosera algo limitado. Caben dos aclaraciones: el número de matriculadas en cada escuela era superior al de las que realmente concurrían y la cantidad de estas últimas fluctuaba con el transcurso del año, abandonando muchas de ellas a medida que el mismo avanzaba. Con esas advertencias como telón de fondo, pasemos a las cifras. En las dos escuelas de la Propaganda Católica, según un informe de la Inspección de Escuelas de la Municipalidadelaborado in situ un día de clase en noviembre de 1916-, se había constatado que en una de ellas había matriculadas 50 sirvientas, asistían en promedio 24 y estaban presentes 22, mientras que en la otra esos valores ascendían a 80,30 y 18, respectivamente. ${ }^{38}$ En septiembre

37. Propaganda Católica (18 de marzo de 1917). LP, p. 1. Destacado del autor.

38. Documentos, 1917, folio 210. AHMC, Córdoba. Para de 1921, cuando ya funcionaba sólo una de esas dos escuelas, la prensa informaba que allí había 96 matriculadas y una asistencia media de 40. ${ }^{39}$ En la Escuela Patronato en 1914 las domésticas eran unas 50 o 60; en 1920, entre 95 y 105; en 1922, había 98 inscriptas y 70 de concurrencia promedio, cifra que se habría elevado a alrededor de 120 en el inicio del ciclo lectivo de $1930 .{ }^{40} \mathrm{El}$ único dato que poseemos para la Escuela Dominical San José de Calasanz, correspondiente al cierre del ciclo escolar de su primer año de funcionamiento, indica la "asistencia ininterrumpida" de 102 alumnas. ${ }^{41}$ Entonces, y sólo a modo de referencia, para mediados de la década de 1910, entre las cuatro escuelas aludidas habrían tenido una concurrencia de alrededor de 300310 sirvientas, aproximadamente.

Los avisos de las escuelas de sirvientas publicados en la prensa católica y las notas periodísticas alusivas a ellas interpelaban a las señoras de casa o patronas de domésticas -no así a éstas últimas- instándolas a que las enviaran a dichas instituciones, con el fin de contar con

1914, la presidenta de la Propaganda Católica afirmaba que entre las dos escuelas dominicales tenían una asistencia de "más de 150 alumnas", dato que muestra consistencia con el provisto para fines de ese año por la Inspección Municipal de Escuelas que hacía un total de 151, distribuidas entre 61 alumnas en una de esas instituciones y 90 en la otra. Documentos,1915, folios 72-73, 78. AHMC, Córdoba.

39. Obras católicas de beneficencia. Escuela dominical para sirvientas (9 de septiembre de 1921). LP, p. 1.

40. Escolares. Escuela Patronato de Sirvientas (2 de diciembre de 1914). LP, p. 4; Instrucción Pública. Escuela Patronato del Carmen (24 de noviembre de 1920). LP, p. 2; Escuela Patronato del Carmen (28 de noviembre de 1920). LP, pp. 2-3; Escuela Patronato del Carmen (25 de abril de 1930). LP, p. 2.

41. Escuela Dominical de S. José de Calasanz (28 de noviembre de 1916). $L P$, p. 3. 
personal idóneo y moralmente calificado. Sin embargo, pese a los beneficios previstos para ambas partes, la asistencia de las domésticas no estaba asegurada, debía ser permanentemente negociada en la cotidianidad entre ellas y las damas que gestionaban esas escuelas, con la participación activa de las patronas respectivas. Éstas se privaban de contar con sus domésticas por unas horas las tardes de domingo y las trabajadoras de parte de su descanso, si lo tenían. Por allí en los avisos de la Propaganda Católica se invitaba a las "dueñas de casa" a que permitieran la ida de sus domésticas a las clases; ${ }^{42}$ además, con frecuencia se señalaba que a cada una de ellas se le otorgaría una constancia que acreditaría su presencia en clase ${ }^{43}$ colaborando así con la patrona en el control de la conducta de su doméstica.

La realidad parece haber sido que las patronas, en caso de estar interesadas en la iniciativa, debían persuadir a sus domésticas para que concurrieran a las escuelas dominicales, convenciéndolas acerca de su utilidad para ellas. Las gacetillas difundidas a través de la prensa por las damas de la Escuela Patronato ofrecen un indicio al respecto. En una de ellas, la ya aludida Blanca expresaba: "Sea pues, un deber para cada señora procurar convencer á sus sirvientas de la gran conveniencia de inscribirse". ${ }^{44}$ Una década después, se afirmaba: "todos debemos aportar decidido concurso, estimulando a las personas que tenemos a

42. La Obra de la Propaganda Católica (5 de abril de 1918). LP, p. 7.

43. La Obra de la Propaganda Católica (5 de abril de 1918). LP, p. 7; Para las dueñas de casa (16 de mayo de 1919). $L P$, p. 2; Feminismo de buena ley (4 de marzo de 1920). LP, p. 4.

44. Blanca (23 de abril de 1912). La escuela-patronato. $L P$, p. 7. Destacado del autor.

14 nuestro servicio, para que asistan a las clases que se dictan gratuitamente". ${ }^{45}$

La necesidad de persuadir, convencer, estimular a las domésticas para que concurrieran tiene valor de indicio de las transformaciones en curso en dirección hacia una menor subordinación de esas trabajadoras. Como parte del proceso de mercantilización del servicio en marcha, los/as patrones/as parecen haber experimentado un debilitamiento de su control sobre el mismo, como contrapartida de una mayor libertad -no por ello incondicionada- de las trabajadoras del sector. ${ }^{46}$

A su vez, las damas que regenteaban las escuelas dominicales hacían su propio trabajo en la misma dirección, tratando de atraer y, sobre todo, retener a las domésticas en ellas. Para ello apelaban a incentivos materiales corporizados en rifas y premios de artículos de uso corriente y al reparto de la propia producción fruto del aprendizaje de corte y confección y economía doméstica, como ropas y comidas ${ }^{47}$ Además, en el acto de clausura del

45. Blanca (23 de abril de 1912). La escuela-patronato. $L P$, p. 7. Destacado del autor.

46. Una manifestación espectacular y extraordinaria del debilitamiento del control patronal o, visto desde su otra cara, de una mayor libertad y capacidad de negociación de las domésticas, dentro del período es la huelga del servicio doméstico de agosto y septiembre de 1929 en la localidad de Bell Ville, de 15.000 habitantes, en el corazón de la pampa agroexportadora cordobesa. Véase: Remedi (2014b, pp. 440-446).

47. Propaganda Católica (18 de marzo de 1917). LP, p. 1; Escuela dominical (22 de febrero de 1920). $L P$, p. 1. Respecto a la Escuela Patronato se consignaba que durante el año 1920 se habían confeccionado 315 piezas de ropa que fueron distribuidas entre las alumnas. Instrucción Pública. Escuela Patronato del Carmen (24 de noviembre de 1920). LP, p. 2. En la escuela de la Propaganda Católica, al finalizar la clase del día se distribuían entre las asistentes "los platos de 
ciclo escolar era común la entrega de premios a quienes lo habían concluido, por sus méritos "en razón a su asistencia, comportamiento y aplicación”. ${ }^{48}$ Esta cuestión no es menor, porque la concurrencia de las domésticas a las clases era fluctuante, dibujando una clara tendencia descendente con el progreso del año. ${ }^{49}$ Las damas no ocultaban las intenciones que motorizaban esas iniciativas. En la Memoria leída en una asamblea de la Propaganda Católica, su presidenta señalaba que la regenta y la inspectora habían puesto "todo su empeño en la buena marcha de las escuelas, halagando a las alumnas con obsequios $y$ rifas".$^{50}$ Lo mismo sucedía en la Escuela Patronato, donde se instaba a sus protectores a enviar donaciones de dinero u objetos; estos últimos servirían de premio para las asistentes, "con lo cual se las atrae haciéndolas cobrar amor y gusto hacia estas clases prácticas dominicales". ${ }^{51}$

Así, la asistencia de las domésticas debía ser continuamente incentivada y negociada; a ellas les incumbía -al menos en parte- decidir

cocina que sirven de lección práctica". Obras católicas de beneficencia. Escuela dominical para sirvientas (9 de septiembre de 1921). $L P$, p. 1.

48. Obras católicas de beneficencia (9 de septiembre de 1921). LP, p. 1. También puede verse: Escolares. Escuela Patronato de Sirvientas (2 de diciembre de 1914). LP, p. 4; Escuelas Dominicales de la Asociación Propaganda Católica (2 de diciembre de 1915). LP, p. 4.

49. Sobre una de las escuelas se señalaba a fines de 1920 que las clases habían iniciado en marzo con "regular matrícula", que había aumentado en abril y mayo, "siendo los primeros meses de ejercicio favorecida con numerosa asistencia, y como en años anteriores, ha terminado con su matrícula y asistencia de alumnas, bastante disminuidas". Escuela Dominical (19 de diciembre de 1920). LP, p. 8.

50. Escuela Dominical (19 de diciembre de 1920). LP, p. 8.

51. Escuela-Patronato (17 de marzo de 1914). LP, p. 4. sobre su incorporación y permanencia en dichas instituciones, mientras que las patronas interesadas $y$, sobre todo, aquellas otras que regenteaban las escuelas debían tratar de persuadirlas, convencerlas, estimularlas para que actuaran en tal sentido. Este esfuerzo era aún mayor porque no sólo chocaba -seguramente- con el disfrute del eventual y escaso tiempo libre de las trabajadoras, sino también por la supuesta limitada inclinación de ellas hacia el aprendizaje. Para la ya citada María Juárez del Campillo, las domésticas eran "el gremio (...) más refractario a toda enseñanza”, según expresiones recogidas de la Memoria de la Propaganda Católica. ${ }^{52}$

Quizás con la intención subsidiaria de fomentar la asistencia y la permanencia de las trabajadoras en las escuelas, y seguramente con la principal de contribuir a una revitalización de los debilitados vínculos paternalistas entre las patronas y ellas, esas instituciones incorporaron algunas funciones adicionales a las educativas. Con ellas se pretendía ofrecer cierta protección a las domésticas frente a las incertidumbres de la vida y del mundo del trabajo. Al mismo tiempo, en la práctica funcionaban como un instrumento de control social, de una pretendida rehabilitación moral de las domésticas mediante la inculcación o promoción de ciertos valores y prácticas, como la religiosidad, la piedad, la previsión, la solidaridad, el esfuerzo, la constancia, el trabajo, el ahorro, el matrimonio religioso, los sacramentos católicos, entre otros.

En esta materia, de los casos considerados, el más revelador es el de la Escuela Patronato. Como su nombre lo indica, se buscaba proteger

52. Escuela Dominical (19 de diciembre de 1920). LP, p. 8. 
y auxiliar a las alumnas-mujeres solteras de entre 13 y 30 años- en ocasión de enfermedad, desempleo, matrimonio y muerte. En un lenguaje fuertemente sesgado por la clase y el género, una de las damas que estaban al frente de la institución promovía la asistencia a la misma publicitando sus beneficios sociales cuando apuntaba: "Tienen además las muchachas en el Patronato, una protección providente y suave, llena de maternales previsiones para los casos de enfermedad, de tomar estado, ó buscar buena colocación la que se encuentra sin ella." Luego añadía: “Qué muchacha podrá negar la grandísima conveniencia de tener asegurada esta protección moral y material para las circunstancias graves y difíciles en que pueda encontrarse?" 53 Incluso se llegaba a plantear un parangón entre la escuela patronato y el mutualismo, subrayando los beneficios materiales pero sin descuidar los espirituales. El diario católico la presentaba como parte de las "obras de previsión y asistencia social" ${ }^{4}$ y las damas la definieron como "una especie de asociación de socorros mutuos en el orden temporal como espiritual, pues el Patronato cuida no solo de proporcionar a las muchachas necesitadas los socorros materiales sino también los espirituales, teniendo además sufragios si alguna de ellas muere. ${ }^{~}{ }^{5}$ Con esa finalidad, entre otras vinculadas con la fe y la espiritualidad, los magros ingresos procedentes de la venta de productos elaborados en las clases prácticas se ahorraban


Escuela-Patronato (26 de marzo de 1915). LP, p. 4.

54. Las escuelas dominicales (2 de noviembre de 1922). $L P$, p. 2.

55. Escuela-Patronato (17 de marzo de 1914). LP, p. 4; Escuela-Patronato (26 de marzo de 1915). LP, p. 4. en una alcancía con el fin de formar un tesoro destinado á beneficio de las muchachas asociadas, á sufragios para las que mueran y á hacer una fiesta religiosa dos veces al año, conducentes a fomentar en ellas el espíritu de piedad. ${ }^{56}$

La Propaganda Católica también incorporó, aunque más tardíamente y con menor desarrollo respecto del caso recién evocado, funciones de protección social que, a la vez que un socorro material, apuntaban también a la inculcación y promoción de ciertos valores y prácticas, entre ellos el ahorro y la previsión. En 1927, la Sociedad Damas Protectoras de Niños Pobres (ex Propaganda Católica) presentaba como novedad para su escuela de sirvientas lo que por entonces definía como anhelo: la creación de una caja de ahorros para cada alumna. ${ }^{57}$ Dos años después, el anhelo parecía haberse concretado, cuando se anunciaba el inicio del nuevo ciclo lectivo y la constitución de "la pequeña caja de ahorros, base del bienestar material de cada una de las asistentes". ${ }^{58}$

Cajas de ahorros y sociedades de socorros mutuos eran instrumentos que -como señala Castel (1997) para la Europa occidental industrial del siglo XIX- podían ser apreciados como los más adecuados para concretar con la mayor eficacia "el mandato de rehabilitación moral de las clases inferiores" (p. 250). Por supuesto, como apunta el mismo Castel (1997), teniendo en vista el nivel de los salarios de los trabajadores, ese tipo de economía valía sobre todo por su valor moralizador, en

56. Escuela-Patronato (28 de marzo de 1911). LP, p. 2.

57. Presta grandes servicios la E. dominical de calle Caseros (13 de agosto de 1927). LP, p. 2.

58. La escuela dominical para jóvenes empleadas (17 de marzo de 1929). LP, p. 3. 
tanto "pedagogía de la previsión" (p. 251). En Córdoba, en el caso particular de la Escuela Patronato, la solidaridad horizontal entre las trabajadoras, propiciada por el mutualismo, aspiraba a mitigar el pauperismo mediante la previsión, pero sometida ésta a la iniciativa y la supervisión permanente y estricta de las damas, inscribiéndose así dentro de un complejo tutelar de las de arriba sobre las de abajo.Más en general, tanto las cajas de ahorros individuales de la escuela de la Propaganda Católica como la alcancía común de la Escuela Patronato, suponían modestas iniciativas de protección social- por medio de la beneficencia en el primer caso y del mutualismo en el segundo-, que se materializaron bajo el impulso, el patrocinio y el control directo de las damas, no así de las trabajadoras que generaban los ingresos que engrosaban esos fondos, fuera a través de pequeñas sumas detraídas de sus retribuciones o procedentes de la venta de los productos elaborados en las clases prácticas, respectivamente.

Como se dijo, en cierto modo se trataba de revitalizar el paternalismo, algo que -en relación con el servicio doméstico- iba más allá de esas prácticas de previsión. Por fuera de esas escuelas, en la vida cotidiana en el interior de los hogares, las patronas debían incentivar el espíritu religioso en el servicio doméstico, apelando para ello a las palabras y también a las obras, además de proporcionarle buenas condiciones laborales. La autotitulada "una señora a la antigua" en 1909 atribuía la mala calidad del servicio a la impiedad y la indiferencia de los patrones respecto de la conducta moral y religiosa del personal doméstico. En las páginas de la prensa católica afirmaba:
El enemigo mortal del servicio es la impiedad (...) que roe y malgasta todos los resortes de la moralidad y las costumbres. No extrañemos que esa doméstica (...) que no asiste jamás á misa los domingos, se nos torne hostil, altanera y haragana. No extrañemos que esa otra (...) que jamás oye la evangélica voz de su párroco, sea la que maltrate y descuide á nuestros hijos. ${ }^{59}$

La solución al problema pasaba por ofrecerle al personal de servicio mejores condiciones de vida y de trabajo- "justo salario y regularmente pagado, alimento abundante y habitación airada é higiénica"- pero sobre todo no debía descuidarse que parte de los "deberes de la señora de la casa hacia sus servidores" consistía en "cuidar de sus almas (...) darles tiempo y libertad para cumplir sus deberes religiosos, incitándoles á ellos con el buen ejemplo y palabras discretas." ${ }^{0} 0$

En la misma dirección de revitalizar el por entonces debilitado paternalismo respecto de las domésticas, y también como parte de las actitudes propias de lo que se estimaba como una buena dueña de casa, las patronas debían granjearse el amor de las trabajadoras del hogar. La citada Blanca era clara y explícita sobre este punto, como se mencionó en páginas anteriores, y consideraba que "el mejor modo de exteriorizar nuestro amor y cuidado hacia nuestras sirvientas" era intentar que se inscribieran en la Escuela Patronato. Así, según su parecer, "á la vuelta de pocos años tendríamos regenerado nuestro servicio

59. Una señora a la antigua (22 de diciembre de 1909). Patrones y servidumbre. $L P$, p. 4.

60. Una señora a la antigua (22 de diciembre de 1909). Patrones y servidumbre. $L P$, p. 4 . Destacado del autor. 
doméstico, cuyo deplorable estado tan preocupada tiene á nuestra sociedad" ${ }^{61}$

\section{Conclusiones}

En las décadas de 1910 y 1920 en la ciudad de Córdoba funcionaron varias "escuelas de sirvientas" que fueron concebidas como instrumentos para regenerar el servicio doméstico femenino. En medio de las críticas que arreciaban en su contra, dirigidas hacia los comportamientos, las competencias para el oficio y las cualidades morales de sus integrantes, y en sintonía con ellas de algunos comentarios nostálgicos acerca de la antigua doméstica -representada como diligente, dócil, fiel, afectuosa, de sentimientos religiososdichas escuelas apuntaron a proveer de buenas trabajadoras para el servicio en el hogar a las familias que las ocupaban. Se trataba de contribuir al mejoramiento material y moral del personal de servicio femenino mediante una enseñanza que combinaba instrucción elemental, desarrollo de competencias prácticas propias del oficio y educación moral y religiosa. En suma, se buscaba formar "buenas y fieles servidoras", vale decir, capacitadas y aptas en el ejercicio del oficio, dóciles, virtuosas, piadosas y, además, fidelizadas, vinculadas con las patronas (y sus familias) a través de lazos que involucraban componentes afectivos, que excedían- y a la vez atravesaban- la relación más estrictamente laboral.

A esos objetivos fundamentales se añadieron otros, complementarios, orientados a proveer de un mínimo auxilio social a las domésticas

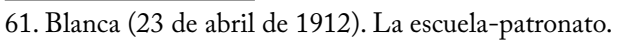
$L P$, p. 7. concurrentes a las escuelas, incorporando así algunas tímidas funciones de previsión y asistencia sociales, a través de la beneficencia o del mutualismo, según el caso considerado, siempre bajo el impulso y la tutela de las damas que gestionaban esas instituciones, a la vez patronas de domésticas en sus hogares. De este modo, frente a un proceso de mercantilización en marcha del servicio doméstico, las escuelas de sirvientas colaboraban en la revitalización de los vínculos paternalistas en el interior de ese espacio de relaciones asimétricas, clasista y cada vez más feminizado que unía a patronas y domésticas, ambas a la vez subordinadas dentro del vigente orden social patriarcal. Se trataba de una "protección providente y suave, llena de maternales previsiones", según palabras de una de las damas que regenteaba la Escuela Patronato. De algún modo, contra esa dominación y su preservación, utilizando para ello como instrumento a las escuelas de sirvientas, apuntaba sus críticas el periódico $L a$ Voz del Interior. Desde su postura vigorosamente anticlerical, descargaba sus invectivas contra su colega católico Los Principios sosteniendo que lo que éste se proponía, al publicitar el funcionamiento de esas instituciones bajo el lema de "feminismo de buena ley", no era más que "“decentificar" el servicio doméstico para que su esclavitud sea más "aristocrática", en vez de promover la "liberación espiritual y cívica de la mujer", como ese título podía llegar a sugerir. $^{62}$

Por otra parte, esas escuelas patrocinadas y gestionadas por la beneficencia católica y agentes eclesiásticos, además de calificar profesionalmente y moralizar al servicio doméstico femenino eran instrumentos

62. Tartufo y el servicio doméstico (24 de marzo de 1921). La Voz del Interior, p. 4. Hemeroteca de la Legislatura, Córdoba. 
adecuados para el ejercicio de la caridad cristiana, llegando a concebírselas a veces como herramientas de un curso de acción que contribuiría al despliegue de una misión redentora de las trabajadoras del sector.

Así, desde esas instituciones de la sociedad civil, bajo la impronta del catolicismo, se trabajaba en "hacer lo social", en la atenuación de los desajustes que acompañaron a la sostenida expansión económica y la modernización social, en este caso concreto, referidos a mujeres, jóvenes, pobres y trabajadoras. Sin embargo, es sugerente que en las escuelas consideradas las domésticas parecen haber sido focalizadas mucho más como trabajadoras que como pobres, siendo ambas cosas. Los discursos emitidos por las damas católicas que regenteaban tales iniciativas aludían a las muchachas o jóvenes "empleadas en el servicio", a esa "clase obrera", a la "mujer obrera", a las que- según se decía- eran tan olvidadas por la sociedad a la vez que llamadas “á ocupar en ella un elevado puesto". ${ }^{63}$

Esas escuelas de sirvientas eran un signo de los tiempos y parte integrante de un movimiento de mayor envergadura de búsqueda de penetración del catolicismo entre los/as trabajadores/as, de su inserción y difusión dentro del mundo del trabajo, aunque sin abandonar su tradicional anclaje en el mundo de los pobres. Entre otras cosas, esas escuelas eran, en parte, un instrumento más de las estrategias del catolicismo en su dinámica de difusión en el terreno social e inserción dentro del mundo del trabajo en particular frente a la modernización económica y social

63. María J. del Campillo, Presidenta de la Asociación Propaganda Católica, a Fernando L. Giménez, Presidente del Concejo Deliberante. 25 de agosto de 1916.

Documentos, 1917, f. 209. AHMC. -con los consecuentes desajustes socialesexperimentados por la Córdoba de entre siglos, especialmente a partir de la década de 1910.

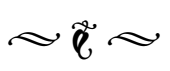




\section{Referencias bibliográficas}

Allemandi, C. (2017). Sirvientes, criados y nodrizas. Una bistoria del servicio doméstico en la ciudad de Buenos Aires (fines del siglo XIX y principios del XX). Buenos Aires: Teseo.

Castel, R. (1997). Las metamorfosis de la cuestión social. Una crónica del salariado. Buenos Aires: Manantial.

Córdoba (1910). Censo General de la Población, Edificación, Comercio, Industria, Ganadería y Agricultura de la Ciudad de Córdoba, levantado en los días 31 de Agosto y $1^{\circ}$ de Septiembre de 1906. Córdoba: La Italia.

Moreyra, B. (1992). La producción agropecuaria cordobesa, 1880-1930 (Cambios, transformaciones y permanencias). Córdoba: Centro de Estudios Históricos.

Moreyra, B. (2009). Cuestión social y politicas sociales en la Argentina. La modernidad periférica. Córdoba, 19001930. Bernal: Universidad Nacional de Quilmes.

Ortiz Bergia, M.J., Reyna, F., Portelli, M. B. Moretti, N. (2015). Procesos amplios, miradas locales: Una historia de Córdoba entre 1880 y 1955. Córdoba: Centro de Estudios Históricos "Prof. Carlos S. A. Segreti”.

Pérez, I. (2018a). Género y cambios en las definiciones legales del servicio doméstico: desmarcación y profesionalización de los choferes. En I. Pérez, R. Cutuli, D. Garazi, Senderos que se bifurcan. Servicio doméstico y derechos laborales en la Argentina del siglo XX. Mar del Plata: Editorial de la Universidad Nacional de Mar del Plata.

Pérez, I. (2018b). Introducción. En I. Pérez, R. Cutuli, D. Garazi, Senderos que se bifurcan. Servicio doméstico y derechos laborales en la Argentina del siglo XX. Mar del Plata: Editorial de la Universidad Nacional de Mar del Plata.

Remedi, F. (2011). Las trabajadoras del servicio doméstico en la modernización argentina de entre siglos. Córdoba (Argentina), 1870-1910. En F. Remedi, T. Rodríguez Morales (Eds.), Los grupos sociales en la modernización latinoamericana de entre siglos. Actores, escenarios y representaciones (Argentina, Chile y México, ss. $X I X-X X)$. Córdoba: Centro de Estudios Históricos "Prof. Carlos S. A. Segreti”. Santiago: Centro de Estudios Culturales Latinoamericanos.

Remedi, F. (2012). "Esta descompostura general de la servidumbre”. Las trabajadoras del servicio doméstico en la modernización argentina. Córdoba, 1869-1906. Secuencia, 84, 43-69. Recuperado de http:// secuencia.mora.edu.mx/index.php/Secuencia/article/view/1168

Remedi, F. (2014a). El "problema del servicio doméstico" en la modernización argentina. Córdoba, 19101930. En F. Remedi, M. Barbosa Cruz (Comps.), Cuestión social, politicas sociales y construcción del Estado Social en América Latina, siglo XX. Córdoba: Centro de Estudios Históricos "Prof. Carlos S. A. Segreti”. México: Universidad Autónoma Metropolitana-Cuajimalpa.

Remedi, F. (2014b). Las trabajadoras del servicio doméstico: entre la subordinación y la negociación en una modernización periférica. Córdoba (Argentina), 1910-1930. Anuario de Historia Regional y de las 
Fronteras, 19(2), 423-450. Recuperado de https://revistas.uis.edu.co/index.php/anuariohistoria/article/ view/4288

Vázquez Lorda, L. (2010). El otro ángel del hogar es mujer, trabajadora y asalariada. Las empleadas domésticas y el catolicismo en la Argentina de los años 1950. En N. Álvarez (Comp.), Familias, género y después... Itinerarios entre lo público, lo privado y lo intimo. Rosario: Prohistoria.

Viel Moreira, L. (2005). Las experiencias de vida en el mundo del trabajo. Los sectores populares del interior argentino (Córdoba, 1861-1914). Córdoba: Centro de Estudios Históricos "Prof. Carlos S. A. Segreti". 